\title{
Enhancing the Conductivity of Cell-Laden Alginate Microfibers With Aqueous Graphene for Neural Applications
}

\author{
Marilyn C. McNamara ${ }^{1}$, Amir Ehsan Niaraki-Asli ${ }^{1,2}$, Jingshuai Guo ${ }^{1}$, Jasmin Okuzono ${ }^{3}$, \\ Reza Montazami ${ }^{1}$ and Nicole N. Hashemi ${ }^{1,4 *}$ \\ ${ }^{1}$ Department of Mechanical Engineering, lowa State University, Ames, IA, United States, ${ }^{2}$ Department of Computer \\ Sciences, lowa State University, Ames, IA, United States, ${ }^{3}$ Department of Chemical Engineering, lowa State University, \\ Ames, IA, United States, ${ }^{4}$ Department of Biomedical Sciences, lowa State University, Ames, IA, United States
}

OPEN ACCESS

Edited by:

Yuris Dzenis,

University of Nebraska-Lincoln

United States

Reviewed by:

Peng-Cheng Ma,

University of Chinese Academy of

Sciences, China

Reza Rashidi,

Alfred State College, United States

*Correspondence:

Nicole N. Hashemi nastaran@iastate.edu

Specialty section:

This article was submitted to Polymeric and Composite Materials,

a section of the journal

Frontiers in Materials

Received: 25 September 2019 Accepted: 27 February 2020 Published: 19 March 2020

Citation:

McNamara MC, Niaraki-Asli AE, Guo J, Okuzono J, Montazami R and Hashemi NN (2020) Enhancing the Conductivity of Cell-Laden Alginate Microfibers With Aqueous Graphene for Neural Applications.

Front. Mater. 7:61.

doi: 10.3389/fmats.2020.00061
Microfluidically manufacturing graphene-alginate microfibers create possibilities for encapsulating rat neural cells within conductive 3D tissue scaffolding to enable the creation of real-time 3D sensing arrays with high physiological relavancy. Cells are encapsulated using the biopolymer alginate, which is combined with graphene to create a cell-containing hydrogel with increased electrical conductivity. Resulting novel alginate-graphene microfibers showed a 2.5 -fold increase over pure alginate microfibers, but did not show significant differences in size and porosity. Cells encapsulated within the microfibers survive for up to 8 days, and maintain 20\% live cells over that duration. The biocompatible aqueous graphene suspension used in this investigation was obtained via liquid phase exfoliation of pristine graphite, to create a graphene-alginate pre-hydrogel solution.

Keywords: alginate microfibers, graphene, conductivity, cell encapsulation, 3D cell coculture, microfluidics, neural cells

\section{INTRODUCTION}

Hydrogel microfibers have many applications in tissue engineering and regenerative medicine, where they are favored for their physical and chemical properties, as well as their reproducible and cell-safe fabrication methods (Bai et al., 2014). A variety of biocompatible polymers are utilized for this method of microfiber creation; among them, alginate is favored within biomedical applications for its good biocompatibility, biodegradability, and low toxicity, as well as its capacity for gelation within mild conditions (Meng et al., 2016; McNamara et al., 2017, 2019b). These factors have garnered interest for alginate for cell encapsulation (Kim et al., 2007; Leong et al., 2016), which requires cells to be present during the gelation of the microfibers, thereby eliminating the possibility of cell loss but requiring cell-safe gelation conditions (Kim et al., 2007).

Hydrogel scaffolds create physiologically relevant platforms for studying cell behavior, and modifications such as increased conductivity may allow for the elucidation of electrical cell-to-cell communication mechanisms within neuronal cell cultures. Existing research created hydrogels with enhanced conductivity to deliver electrical stimulation to cells to study or control cell response, viability, and regeneration potentials (Mohanty et al., 2013; Sirivisoot et al., 2014; Mawad et al., 2016; Inal et al., 2017; Wang et al., 2017; Niemczyk et al., 2018; Osipova et al., 2018; Zhang et al., 2018). However, conductive biocompatible hydrogels remain underutilized as $3 \mathrm{D}$ electro-sensing cell culture scaffoldings (Acar et al., 2014). Encapsulating cells within the conductive hydrogel furthermore restricts the spatial location of the cells, better enabling long-term studies. 
While there are a range of ways to enhance the conductivity of materials, only some are suitable for biomedical applications. Since its discovery in 2004, graphene, a one-atom-thick, twodimensional honey-combed arrangement of $s p^{2}$ hybridized carbons, has drawn considerable attention in nanoscience. It has become known as a functional material in electrophysiology applications due to its biocompatibility, high conductivity, and mechanical properties, which are preferable to other compounds such as reduced graphene oxide (Feng and Liu, 2011; Thayumanavan et al., 2014; Ahadian et al., 2015; Reina et al., 2017). However, challenges arise when non-toxic aqueous suspensions of graphene are required, as is the case when both cells and graphene are encapsulated within a hydrogel. In order to fabricate a non-toxic aqueous suspension of graphene, both the chemical and mechanical manipulation of graphite is necessary.

Chemically, graphite exfoliation is assisted by the inclusion of suitable surfactants, which reduce interfacial tensions to aid in suspension (Ghanem and Abdel Rehim, 2018).

Surfactants typically used to aid in this are typically highly toxic (Ahadian et al., 2015). However, a water-soluble protein called bovine serum albumin (BSA) has recently shown promise in aiding with graphene dispersion due to its ability to make non-covalent bonds with both positively and negatively charged particles (Ahadian et al., 2015; Gianak et al., 2018). BSA alters the intrinsic properties of graphene nanosheets only minimally, as it bonds with graphene non-covalently, thereby enabling the creation of a highly stable, non-aggregating aqueous graphene solution that may be stored in ambient conditions over extended periods (Ahadian et al., 2015).

Common mechanical techniques for graphene dispersion involve using sonication, but this method requires additional materials and electrochemical procedures to maintain a stable aqueous graphene solution, which affects the biocompatibility of the resulting graphene solution (Ahadian et al., 2015). Graphene oxide may be reduced either thermally or chemically; however, the desired characteristics of the synthesized graphene may not be easily maintained, and requires extensive use of cytotoxic chemicals and procedures (Ahadian et al., 2015). Another direct route for non-cytotoxic dispersions of graphene is the liquid phase exfoliation and fragmentation of graphite through sonication and magnetic stirring in BSA, or through mechanically induced shear force, such as can be applied from a kitchen blender (Ahadian et al., 2015; Pattammattel and Kumar, 2015; Ismail et al., 2017). Raman spectra of graphene produced previous work has shown that these methods are capable of creating few-layer graphene, with an $\left(I_{D} / I_{G}\right)_{\text {Graphene }}=0.11$ (Guo et al., 2019).

Previously, conductivities of hydrogels were modified by the addition of synthetic polymers such as polypyrrole or poly(3,4ethylenedioxythiophene) polystyrene sulfonate (PEDOT:PSS) (Bu et al., 2018; Heo et al., 2019). Other works have shown that the addition of graphene, graphene oxide, or reduced graphene oxide can also improve the electrical properties of resulting hydrogels (Thayumanavan et al., 2014; Liu et al., 2016, 2017; Osipova et al., 2018; Niaraki-Asli et al., 2019). However, due to the aforementioned difficulties in creating cell-safe solutions of graphene, this highly conductive and promising material has been underrepresented in the creation of cell-encapsulating hydrogels, particularly in microfiber form, where graphene oxide has been more commonly utilized (Gonzalez-Mayorga et al., 2017; Serrano et al., 2018). Microfibers were selected due to their ability to mimic spatially organized 3D environments with controllable cell density for extended periods of time (Onoe and Takeuchi, 2015), while a microfluidic platform was chosen for its gentle polymerization conditions and tunable control over the spatio-temporal locations of the cells (McNamara et al., 2017).

To create microfibers, a microfluidic device was used to aid and control in the gelling of alginate. Microfluidics has become a key platform for multiple biological studies due to their ability to mimic physiological conditions and their high throughput mechanisms (Sechi et al., 2013; Caplin et al., 2015; Hashemi et al., 2016; Pemathilaka et al., 2019). For fiber fabrication, microfluidics allows for the continuous creation of fibers with highly tunable geometries and mechanical properties (McNamara et al., 2017, 2019b). The described microfluidic method allows precise control over the diameter and crosssectional shape of the microfiber through the ability to vary microchannel device size and geometry, as well as the flow rate ratio (FRR) between the core and sheath fluids (Shin et al., 2007; Sharifi et al., 2016a,b,c; McNamara et al., 2017). Different FRRs impact the characteristics of the fibers, affecting their size, shape, and mechanical properties (Kang et al., 2012; Anderson et al., 2015; Bozza, 2015). Similarly, since alginate is gelled by contact with calcium ions, introducing calcium chloride dihydrate $\left(\mathrm{CaCl}_{2} \cdot \mathrm{H}_{2} \mathrm{O}\right)$ into the sheath fluid allows for solidification within the microfluidic device and further control over the mechanical properties of the fibers. By optimizing the concentration of $\mathrm{CaCl}_{2} \cdot \mathrm{H}_{2} \mathrm{O}$, it is possible to solidify fibers enough to be gathered within a pure water collection bath; however, fibers are gathered in a $\mathrm{CaCl}_{2} \cdot \mathrm{H}_{2} \mathrm{O}$ solution to further increase their strength (McNamara et al., 2019a,b).

Creating a physiologically relevant platform allows for realtime 3D conductivity measurements, thereby allowing for rapid detection of cellular responses to chemical or mechanical inputs. This study aims to provide preliminary proof on the applicability of such scaffolds.Cutting-edge breakthroughs in the fabrication of biocompatible and stable aqueous graphene suspensions enable the encapsulation of both graphene and cells within the alginate hydrogel, therebyproving the concept that the addition of a highly conductive element within a biocompatible hydrogel can pave the way to real-time sensing platforms with control over cell location.

\section{MATERIALS AND METHODS}

\section{Preparation of Graphene Solution}

For this work, $20 \mathrm{~g}$ of graphite (Synthetic graphite powder $<20 \mu \mathrm{m}$, Aldrich Chemistry, St. Louis, MO) and $650 \mathrm{mg}$ of BSA (A7906, Sigma-Aldrich, St. Louis, MO), were mixed in a kitchen blender with $200 \mathrm{~mL}$ of DI water for $25 \mathrm{~min}$. The graphene solution was allowed to rest for $\sim 24 \mathrm{~h}$ to allow for remaining graphite to settle out of the solution. The supernatant was used as the graphene solution. 


\section{Preparation of Solutions and Frames}

To prepare the core solutions, $0.1 \mathrm{~g}$ of alginate powder (very low viscosity, Product Number A18565 Alfa Aesar, Ward Hill, MA) and a magnetic stirrer were soaked overnight in ethanol under UV light from a biological fume hood. Once dry, $1.8 \mathrm{~mL}$ of WFI-Quality Cell Culture grade water (Corning, Corning, $\mathrm{NY}$ ) and $1.8 \mathrm{~mL}$ of freshly mixed UV-sterilized graphene solution were introduce. The resulting solutions were mixed with $0.2 \mathrm{~mL}$ of cell suspension $\left(1.1725 \times 10^{7}\right.$ cells $\left.\mathrm{mL}^{-1}\right)$ to form a $5 \%$ alginate solution. Various other concentrations of alginate were tried, but a $5 \%$ alginate solution was viscous enough to resist shear force within the microfluidic channel, thereby producing smoother fibers.

The sheath solution was created by dissolving $20 \%$ poly(ethylene glycol) (PEG) $\left(\mathrm{M}_{\mathrm{n}}=20,000\right.$, Aldrich Chemistry, St. Louis, MO) and $0.04 \% \mathrm{CaCl}_{2} \cdot 2 \mathrm{H}_{2} \mathrm{O}$ (Fisher Chemical, Waltham, MA) into DI water. The collection bath was $7.5 \%$ PEG, $2.5 \% \mathrm{CaCl}_{2} \cdot 2 \mathrm{H}_{2} \mathrm{O}$. Both solutions were sterilized using a $0.22 \mu \mathrm{m}$ sterile syringe filter.

Cell-laden fibers were introduced into the collection bath, where they sank before they were removed with tweezers and were wrapped around polydimethylsiloxane (PDMS) frames. Frames were fabricated by introducing $0.5 \mathrm{~g}$ of mixed PDMS into 12 -well plates and thermosetting them at room temperature for 1 day. Once solidified, two sides of the circle were removed and the center was removed with a hole punch.

\section{Fabrication of Microfluidic Devices}

The microfluidic devices used in this study are fabricated by thermosetting polydimethyl sulfoxide (PDMS) onto photolithographic molds on silicon wafers. The design of the molds has been discussed previously (Sharifi et al., 2016a,b,c; McNamara et al., 2019b; Sharifi et al., 2019). Briefly, the channel had dimensions of $130 \mu \mathrm{m} \times 390 \mu \mathrm{m}$. Four diagonal grooves on the top and bottom of the channel allow for further shaping of the core fluid; these chevrons are $200 \mu \mathrm{m}$ apart and have dimensions of $130 \mu \mathrm{m} \times 100 \mu \mathrm{m}$. The main chamber of this device was $1 \mathrm{~mm}$ longer than previously used to ensure sufficient time within the microfluidic device for solidification of the core solution (Sharifi et al., 2016c).

To create the device, PDMS (Dow Corning, Midland, MI) was mixed in a 1:10 ratio of elastomer curing agent to elastomer base. Mixed PDMS was solidified on the molds at $80^{\circ} \mathrm{C}$ for $25 \mathrm{~min}$. The two halves were bonded using plasma cleaning.

\section{Cell Culture}

Rat dopaminergic neural cells (N27s) were received as a generous gift from the Department of Biomedical Sciences at Iowa State University. Cells were cultured in maintenance media (MM) containing RPMI Medium 1640 (1X) (Gibco Life Technologies Limited, Paisley, UK), which was supplemented with $10 \%$ fetal bovine serum (FBS) (One Shot format, ThermoFisher Scientific, Waltham, MA), $1 \%$ penicillin $\left(10,000 \mathrm{U} \mathrm{mL}^{-1}\right)$-streptomycin $\left(10,000 \mu \mathrm{g} \mathrm{mL}^{-1}\right)$ (Gibco, Waltham, MA), and 1\% L-glutamine $200 \mathrm{mM}$ (100X) (Gibco Life Technologies Corporation, Grand Island, NY).
Cells were cultured in T-25 flasks and were passaged at 70\% confluency and were maintained in a $37^{\circ} \mathrm{C}, 5 \% \mathrm{CO}_{2}$ atmosphere. Cells were passaged three times before use. For encapsulation, cells were trypsinized and $0.2 \mathrm{~mL}$ of cell suspension $(1.1725$ $\times 10^{7}$ cells $\mathrm{mL}^{-1}$ ) was added to the alginate and graphenealginate solutions.

\section{Fabrication of Alginate-Graphene Microfibers}

Before use, microfluidic devices were flushed with $70 \%$ ethanol and were placed under UV light for a minimum of $5 \mathrm{~h}$. Sterilized solutions were placed into pre-sterilized $\mathrm{BD}$ syringes under a biological fume hood. The solutions were introduced into the microchannel via a double syringe pump (Cole-Parmer, Veron Hills, IL) with a FRR of $40: 10 \mu \mathrm{L} \min ^{-1}: \mu \mathrm{L} \min ^{-1}$ (sheath:core), which was optimized to provide sufficient time within the microfluidic device for gelation of the core solution without causing clogging. The microfluidic schematic can be seen in Figure 1.

\section{Porosities of Microfibers}

To study the porosities of the microfibers, a minimum of $n=3$ fibers were fabricated directly onto u-shaped copper wire frames. Fibers were allowed to dry overnight, and then were weighed. Afterwards, fibers were soaked in DI water overnight, and their wet weights were measured after excess liquid was removed by blotting the surface of the fibers with a Kimtech wipe. The wet volume was approximated using the diameter on as measured by a Zeiss Axio Observer Z1 Inverted Microscope. The porosities were then calculated using the Equation (1), where $M_{\mathrm{w}}$ and $M_{d}$ are the wet and dry weights of the fibers, $V$ is the volume of the wet fiber, and $\rho$ is the density of the liquid:

$$
\text { Porosity }=\frac{M_{w}-M_{d}}{\rho V}
$$

\section{Electrical Characterization}

Cell-free fibers were fabricated in a non-sterile environment and were mounted on paper frames to dry. Once dry, an average of three fibers were mounted on plastic using electrically conductive carbon tape to allow for an electronic connection between an electrode and the fibers. Colloidal silver paste was placed over fiber to ensure ohmic contact. Since dry fibers are straight, the resistance of the fibers was measured using a Sinometer MS8269 Digital Multimeter (ShenZhen, China), and the conductivity was calculated with Equation (2), where $\Omega$ is the conductivity, $L$ is the length of the fiber, $R$ is the resistance of the fiber, and $A$ is the cross-sectional of area of the fiber. Fibers were modeled as cylinders, with radii calculated from the wide and narrow size of dry fibers ( $\mathrm{Lu}, 2016)$.

$$
\Omega=\frac{L}{R A}
$$

\section{Live-Dead Cell Assays}

To perform the live-dead cell assays, a $10 \mu \mathrm{M}$ CellTracker $^{\mathrm{TM}}$ CMFDA and $8 \mu \mathrm{m}$ propidium iodide (PI) (Invitrogen, Carlsbad, 


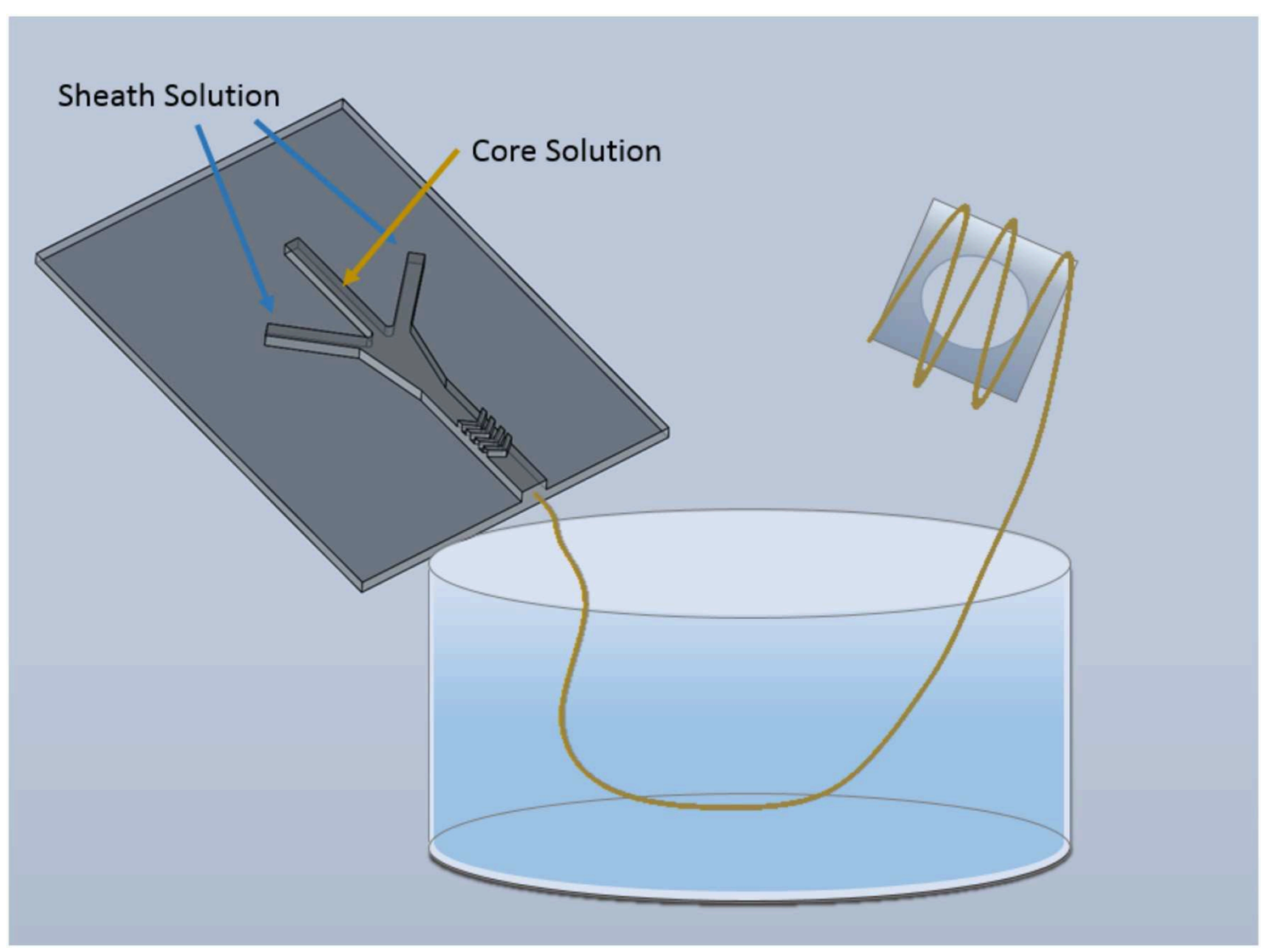

FIGURE 1 | Schematic of microfluidic device for alginate and graphene-alginate microfiber fabrication. Fibers were gelled within the microfluidic device and were extruded into a $2.5 \% \mathrm{CaCl}_{2} \cdot 2 \mathrm{H}_{2} \mathrm{O}, 7.5 \%$ PEG collection bath. Once fabricated cell-encapsulated fibers were wound onto sterilized PDMS frames.

CA) was used as dye solution. On the desired time point, MM was carefully removed from the 12 well plate, and the wells were rinsed with FBS-free RPMI media $(500 \mu \mathrm{L})$. After, dye media (500 $\mu \mathrm{L}$ ) was introduced and was incubated for $20 \mathrm{~min}$ at $37^{\circ} \mathrm{C}$ and $5 \% \mathrm{CO}_{2}$. Once incubation was complete, dye media was removed and fibers were suspended into FBS-free RPMI media $(500 \mu \mathrm{L})$ to keep samples wet during imaging.

\section{Imaging}

Fluorescent images were captured using a Zeiss Axio Observer Z1 Inverted Microscope. Initial processing was carried out with AxioVision Special Edition 64-bit software, but further editing was completed in Adobe Photoshop CC 2018.

SEM images were generated by drying samples overnight and mounting them using electrically conductive carbon and copper tape. Samples were analyzed using a JCM-6000 NeoScope Benchtop SEM with an accelerating voltage of $15 \mathrm{kV}$.

\section{Statistical Analysis}

Statistical analysis was carried out with R Project Statistical Software to conduct an Analysis of Variance (ANOVA) to compare the means across samples.

\section{RESULTS AND DISCUSSION}

\section{Fabrication of Alginate and Graphene-Alginate Microfibers}

Both 5\% alginate and $9 \%$ graphene, 5\% alginate microfibers were successfully fabricated utilizing a sheath solution of $0.04 \%$ $\mathrm{CaCl}_{2} \cdot 2 \mathrm{H}_{2} \mathrm{O}, 20 \%$ PEG. Samples were gathered in a collection bath of $7.5 \% \mathrm{PEG}, 2.5 \% \mathrm{CaCl}_{2} \cdot 2 \mathrm{H}_{2} \mathrm{O}$. Since samples are oval in shape, the analysis was carried out on both a long (wide) and short (narrow) axis (Figure 2). Cross-sectional and longitudinal images of both alginate $\left(a_{1}-a_{2}\right)$ and graphene-alginate $\left(c_{1}-c_{2}\right)$ can also be observed in Figure 2. After SEM analysis, it was determined that there was no significant difference between the sizes of the alginate and graphene-alginate samples, as is evidenced by Figure $\mathbf{2 b}$. This is to be expected, since graphene flakes generated by the kitchen blender method small enough in size that they do not drastically change the behavior of the alginate as it passes through the microfluidic device. Previous works have shown that the sizes of microfluidicallygenerated microfibers can be successfully tuned by adjusting the concentrations of the core fluid, the sheath fluid, and the collection bath; the FRR used to fabricate fibers also plays a significant role in determining their size (Sharifi et al., 2016a,b; McNamara et al., 2017, 2019b). 

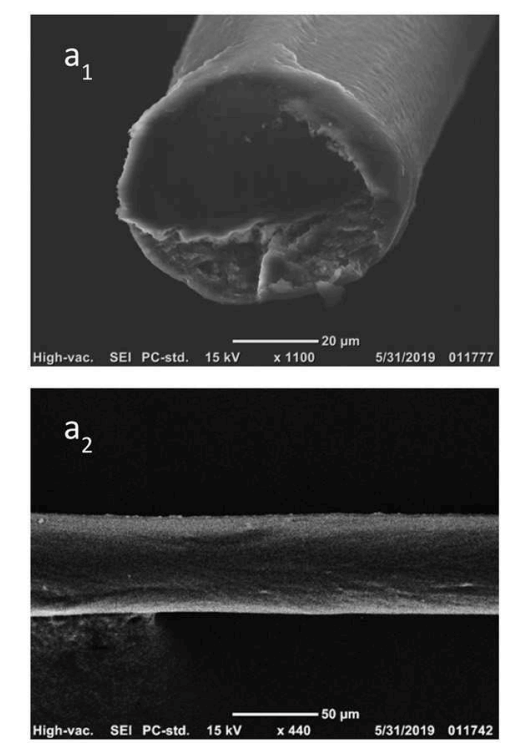
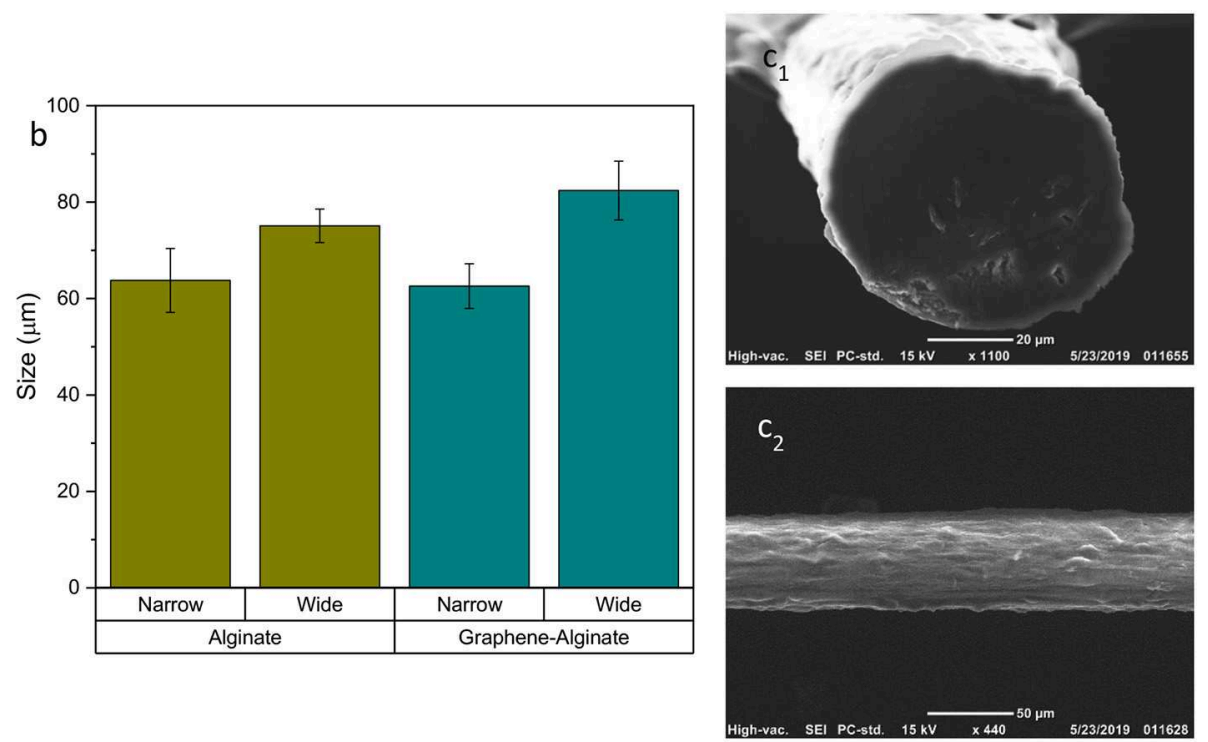

FIGURE 2 | SEM analysis of alginate $\left(\mathbf{a}_{\mathbf{1}}, \mathbf{a}_{\mathbf{2}}\right)$ and graphene-alginate $\left(\mathbf{c}_{\mathbf{1}}, \mathbf{c}_{\mathbf{2}}\right)$ fibers. Fibers were created microfluidically with a core fluid of $5 \%$ alginate and $9 \%$ graphene, and a sheath fluid of $20 \%$ PEG, $0.04 \% \mathrm{CaCl}_{2} \cdot 2 \mathrm{H}_{2} \mathrm{O}$, with a FRR of $40: 10 \mu \mathrm{L} \mathrm{min} \mathrm{m}^{-1}: \mu \mathrm{L} \mathrm{min}^{-1}$. They were gathered in a bath of $7.5 \%$ PEG, $2.5 \%$ $\mathrm{CaCl}_{2} \cdot 2 \mathrm{H}_{2} \mathrm{O}$. An ANOVA test was performed in $\mathrm{R}$ Statistical Software which showed no significant differences between the narrow and wide geometries of each respective sample group. (b) Numerical analysis of the cross-sectional sizes of alginate and graphene alginate microfibers. Fibers are not perfectly round, and therefore have both a longer (wide) and shorter (narrow) axes. Error bars represent \pm 1 standard deviation.

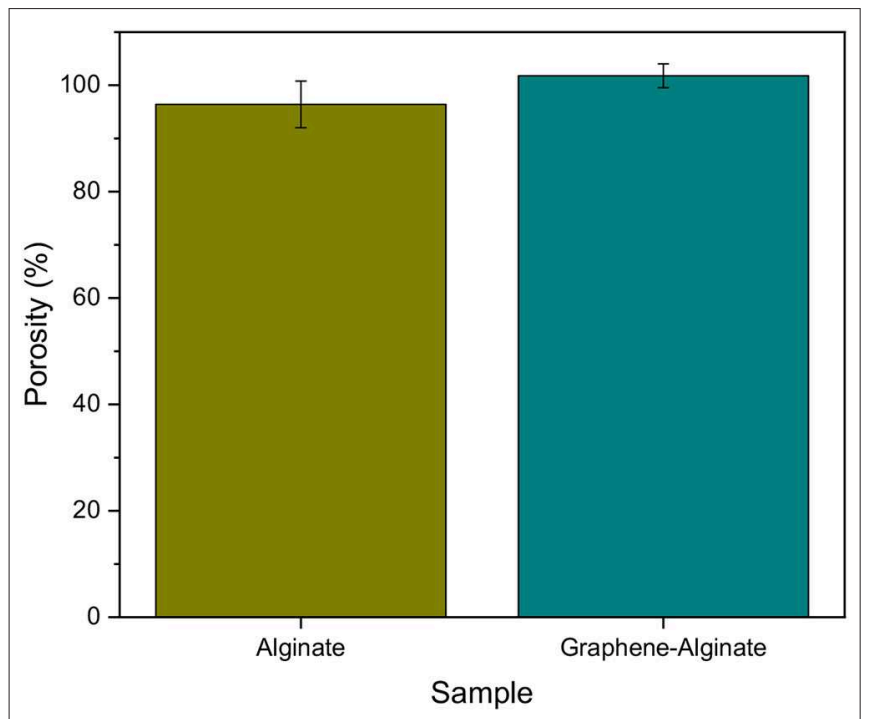

FIGURE 3 | Porosities of $5 \%$ alginate and $9 \%$ graphene, $5 \%$ alginate microfibers created within a microfluidic device with a FRR of $40: 10 \mu \mathrm{L}$ $\mathrm{min}^{-1}: \mu \mathrm{L} \mathrm{min}{ }^{-1}$ and a sheath of $0.04 \% \mathrm{CaCl}_{2} \cdot 2 \mathrm{H}_{2} \mathrm{O}, 20 \%$. Samples were gathered in a collection bath of $7.5 \% \mathrm{PEG}, 2.5 \% \mathrm{CaCl}_{2} \cdot 2 \mathrm{H}_{2} \mathrm{O}$. Error bars indicate \pm 1 standard deviation.

\section{Characterization of Fiber Porosities}

The porosity of hydrogels used for cell encapsulation plays a significant role in long-term cell health and viability, as it affects the diffusion of nutrients into and waste out of the fiber boundaries (McNamara et al., 2017) In order to investigate the porosities of alginate and graphene-alginate microfibers, fibers

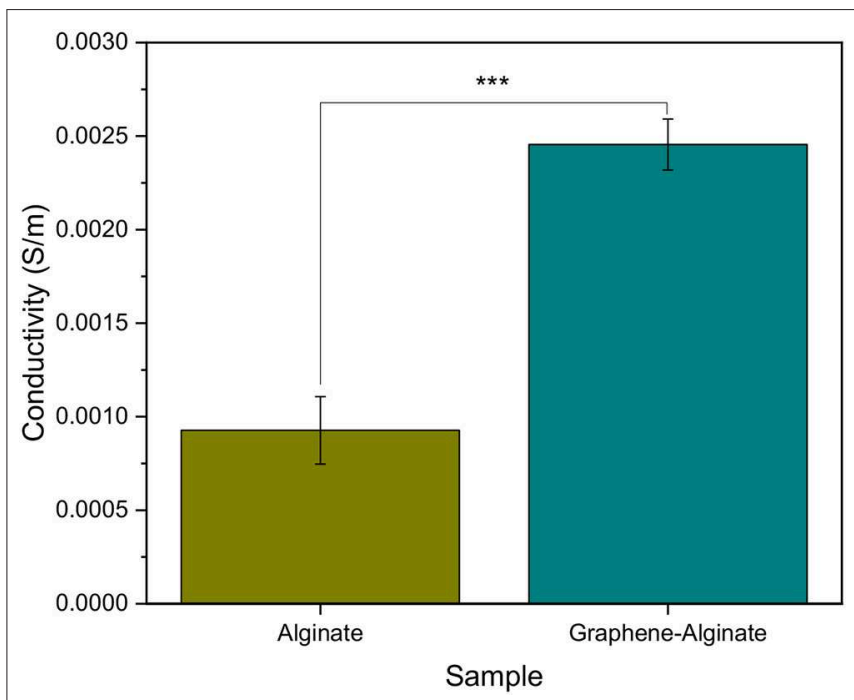

FIGURE 4 | Conductivity of pure 5\% alginate and 9\% graphene, 5\% algiante microfibers microfluidically created with a FRR of $40: 10 \mu \mathrm{L} \mathrm{min}{ }^{-1}: \mu \mathrm{L} \mathrm{min}^{-1}$ and a sheath of $0.04 \% \mathrm{CaCl}_{2} \cdot 2 \mathrm{H}_{2} \mathrm{O}, 20 \%$. Samples were gathered in a collection bath of $7.5 \% \mathrm{PEG}, 2.5 \% \mathrm{CaCl}_{2} \cdot 2 \mathrm{H}_{2} \mathrm{O}$. Graphene-alginate samples were significantly more conductive than the alginate samples. Analysis of Variance was carried out in R Statistical Software. ${ }^{* * *}$ Significantly different at $p$ $\leq 0.001$. Error bars indicate \pm 1 standard deviation.

were fabricated onto copper frames, which allowed for the measurement of wet and dry weights. There were no significant differences between the porosities of the alginate and graphenealginate samples (Figure 3). This is to be expected, particularly 


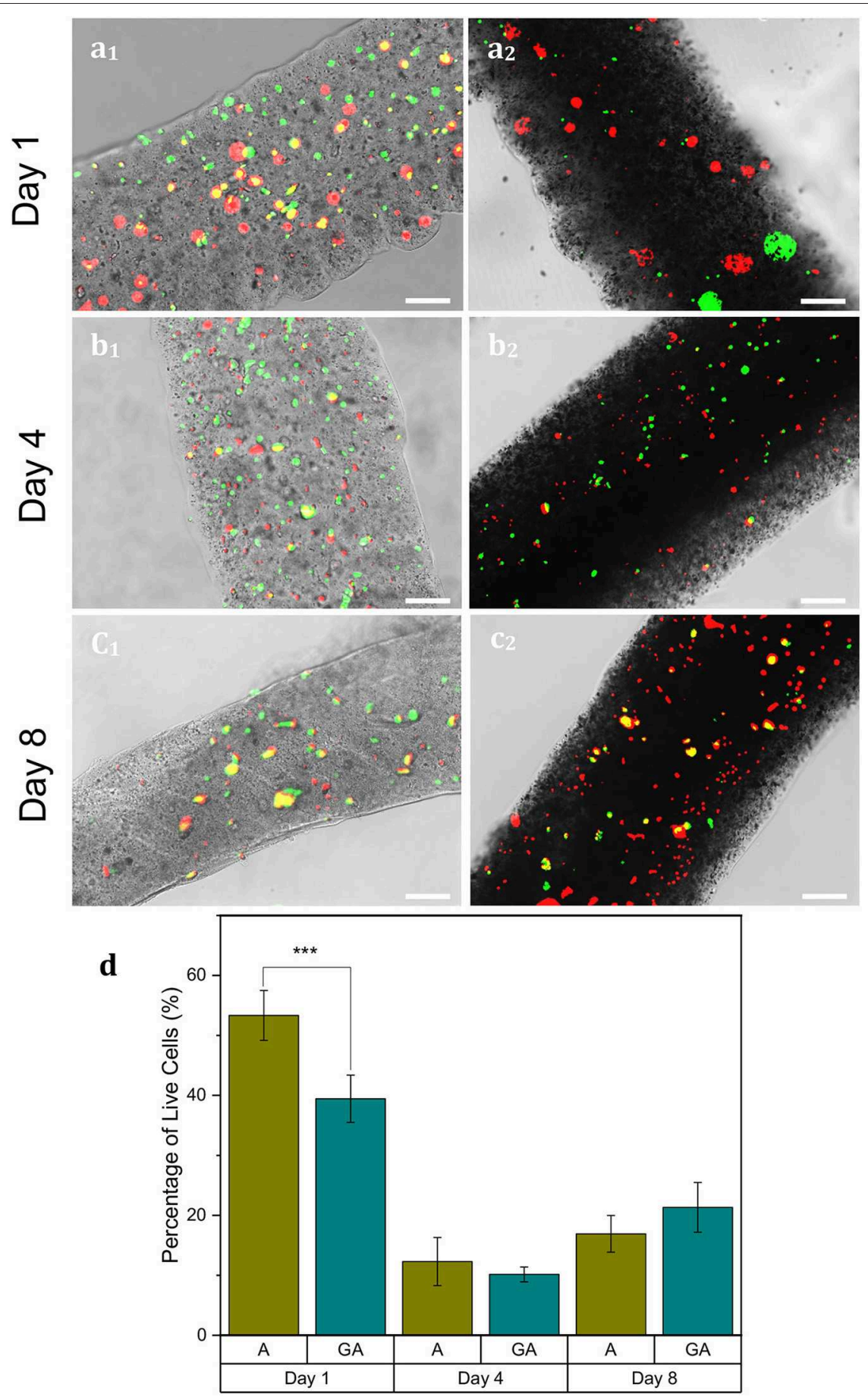

FIGURE 5 | N27 cells encapsulated within 5\% alginate $\left(\mathbf{a}_{\mathbf{1}}-\mathbf{c}_{\mathbf{1}}\right)$ and $9 \%$ graphene, 5\% alginate (GA) $\left(\mathbf{a}_{\mathbf{2}}-\mathbf{c}_{\mathbf{2}}\right)$ microfibers which were microfluidically created with a sheath of $0.04 \% \mathrm{CaCl} 2 \cdot 2 \mathrm{H}_{2} \mathrm{O}, 20 \% \mathrm{PEG}$ and a FRR of $40: 10 \mu \mathrm{L} \mathrm{min} \mathrm{m}^{-1}: \mu \mathrm{L} \mathrm{min}{ }^{-1}$. Samples were gathered in a collection bath of $7.5 \% \mathrm{PEG}, 2.5 \% \mathrm{CaCl} \cdot 2 \mathrm{H}_{2} \mathrm{O}$. A

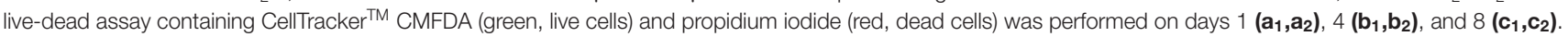
Scale bars indicate $100 \mu \mathrm{m}$. (d) A statistical analysis using R Statistical Software was used to analyze the data. ${ }^{* \star \star} p \leq 0.001$. Error bars indicate \pm 1 standard deviation.

since graphene particles will not interact strongly with water molecules. Fibers of both samples exhibited high porosities; since excess DI water was removed from the surface of the fibers, this indicates that they are capable of absorbing close their own weight in water, as is common in hydrogels (McNamara et al., 2017). 


\section{Conductivity}

Aqueous solutions of graphene drastically changed the appearance of microfibers, causing them to be black instead of transparent when wet. As observed in Figures $\mathbf{2} \mathbf{a}_{2}, \mathbf{c}_{2}$, graphene was well-distributed throughout the body of the fibers. Introduction of graphene into alginate microfibers significantly increased the conductivity of the resulting hydrogels by a factor of 2.5 , achieving an overall conductivity of $0.0025 \mathrm{~S} \mathrm{~m}^{-1}$ for dry fibers mounted using carbon tape and colloidal silver paste (Figure 4). This indicates that the graphene flakes within the fibers are consistently dispersed enough to shorten diffusion distance of electrons, thereby aiding in the transportation of electrons through the bulk of the fiber and increasing its electrical conductivity (Wu and Zhong, 2019) Other cell-laden conductive hydrogels, which have thus far taken the form of films, achieved conductivities of $0.2 \mathrm{~S} \mathrm{~m}^{-1}$ (Dong et al., 2016) and $0.02 \mathrm{~S} \mathrm{~m}^{-1}$ (Wang et al., 2018) for wet samples. These films are based on synthetic polymers and were biocompatible, but lacked the high degree of control over cell culture geometry that microfibers can provide. In comparison, the conductivity of native human brain tissue ranges from 0.05 to $0.24 \mathrm{~S} \mathrm{~m}^{-1}$, with an average of $0.12 \mathrm{~S} \mathrm{~m}^{-1}$ (Akhtari et al., 2016) link Methods to increase the conductivity of the alginate microfibers to better match the conductivity of brain tissues might include incorporating synthetic polymers or increasing the concentration and dispersion of graphene flakes in an aqueous solution by further refining the lab-based process.

\section{Encapsulation of N27 Cells in Graphene/Alginate Solutions}

Cells were successfully encapsulated within alginate and graphene-alginate hydrogels, and survived for up to 8 days, as can be seen in Figure 5. Initially, alginate fibers held significantly more live cells than the corresponding graphenealginate microfibers, as can be seen in Figures $5 \mathbf{a}_{1}, \mathbf{a}_{2}, \mathbf{d}$. However, by the fourth day (Figures $\mathbf{5}_{\mathbf{1}}, \mathbf{b}_{\mathbf{2}}$ ), the differences between the samples were insignificant, which is a trend that held until the eighth day (Figures $\mathbf{5} \mathbf{c}_{1}, \mathbf{c}_{2}$ ). Between days 1 and 4 , the number of live cells within both microfiber samples dropped significantly. This may be because the conditions within the microfibers are not conducive to long-term cell survival; however, at this time cells were also observed on the bottom of the well plates. Therefore, live cells were capable of migrating beyond the fiber boundary, thereby decreasing the number of live cells within the fibers. However, with modifications to the microfibers, the rate of cell egress can be controlled to suit the desired application. This can be done by increasing the porosities of the microfibers, or by other chemical modifications, such as the inclusion of arginineglycine-aspartic acid (RGD) (Anderson et al., 2015; Ho et al., 2017; Santos et al., 2019).

Increasing the amount of live cells within fiber boundaries would be beneficial for long-term experiments. This can be accomplished by increasing the cross-linking of the hydrogel fiber, thereby restricting the ability of cells to migrate outside of the fibers. Additionally, chemically functionalizing the alginate hydrogel during gelation can increase the amount of cell interactions, thereby improving the biocompatibility of the microfibers (Anderson et al., 2015; Wei et al., 2017).

\section{CONCLUSIONS}

Presented here are cell-laden graphene-alginate hydrogels in the form of microfibrous scaffoldings. These fibers have the potential to deliver and receive electrical signals to cells, thereby showing great promise in a wide number of fields, as these mechanisms are known to affect cell behaviors such as differentiation, orientation, mobility, and more (Sirivisoot et al., 2014; Wang et al., 2017; Osipova et al., 2018; Zhang et al., 2018). Current conductive hydrogels in biomedical fields take the form of membranes (Escalona et al., 2012), gels (Liu et al., 2016; Bu et al., 2018), or films (Dong et al., 2016; Liu et al., 2017; Wang et al., 2018).

Introducing graphene into alginate microfibers did not significantly affect their sizes or porosities, but their conductivities were significantly increased by a factor of 2.5. Although cell viability was significantly higher in alginate fibers after $24 \mathrm{~h}$, once cells had been encapsulated $96 \mathrm{~h}$, the difference in the percentage of live cells between the samples was not statistically significant. While there was a drop in the number of live cells in the fibers between 24 and $96 \mathrm{~h}$, this could indicate that live cells were able to migrate out of the fiber boundaries, since cells were observed attached to the bottom of the well plate. This has high promise for applications where cells should be allowed to leave the hydrogel and permeate native tissues. However, this migration can be controlled by a number of factors.

\section{DATA AVAILABILITY STATEMENT}

All datasets generated for this study are included in the article/supplementary material.

\section{AUTHOR CONTRIBUTIONS}

$\mathrm{MM}, \mathrm{AN}-\mathrm{A}, \mathrm{JO}$, and $\mathrm{NH}$ contributed conception and design of the study. MM, AN-A, JG, and JO conducted the experiments. $\mathrm{MM}$ wrote the first draft of the manuscript. RM and $\mathrm{NH}$ acquired funding. All authors contributed to manuscript revision, read, and approved the submitted version.

\section{FUNDING}

This work was partially supported by the Office of Naval Research Grant (ONR) N000141612246, and ONR Grant N000141712620, as well as the Iowa State University Multiscale Sensing Actuation and Imaging (MoSAIc) Research Experience for Undergraduates program, and the Iowa State University Honor's Program.

\section{ACKNOWLEDGMENTS}

We thank Dr. Farrokh Sharifi, Deepak George-Thomas, and Dr. Rajeendra Pemathilaka for their assistance. We thank Dr. Anumantha Kanthasamy for the gift of Rat dopaminergic neural cells (N27s). 


\section{REFERENCES}

Acar, H., Cinar, S., Thunga, M., Kessler, M. R., Hashemi, N. N., and Montazami, R. (2014). Study of physically transient insulating materials as a potential platform for transient electronics and bioelectronics. Adv. Funct. Mater. 201:4. doi: 10.1002/adfm.201304186

Ahadian, S., Estili, M., Surya, V. J., Ramon-Azcon, J., Liang, X., Shiku, H., et al. (2015). Facile and green production of aqueous graphene dispersions for biomedical applications. Nanoscale 7, 6436-6443. doi: 10.1039/C4NR07569B

Akhtari, M., Emin, D., Ellingson, B. M., Woodworth, D., Frew, A., and Mathern, G. W. (2016). Measuring the local electrical conductivity of human brain tissue. J. Appl. Phys. 119:064701. doi: 10.1063/1.4941556

Anderson, T., Auk-Emblem, P., and Dornish, M. (2015). 3D cell culture in alginate hydrogels. Microarrays 4, 133-161. doi: 10.3390/microarrays4020133

Bai, Z., Mendosa Reyes, J. M., Montazami, R., and Hashemi, N. (2014). On-chip development of hydrogel microfibers from round to square/ribbon shape. $J$. Mater. Chem. A 2:4878. doi: 10.1039/c3tal4573e

Bozza, A. (2015). Alginate-based hydrogels for central nervous system tissue regeneration (Ph.D. thesis), University of Trento, Trento, Italy.

Bu, Y., Xu, H.-X., Li, X., Xu, W.-J., Yin, Y.-x., Dai, H.-l., et al. (2018). A conductive sodium alginate and carboxymethyl chitosan hydrogel doped with polypyrrole for peripheral nerve regeneration. RSC Adv. 8, 10806-10817. doi: $10.1039 / \mathrm{C} 8 \mathrm{RA} 01059 \mathrm{E}$

Caplin, J. D., Granados, N. G., James, M. R., Montazami, R., and Hashemi, N. N. (2015). Microfluidic organ-on-a-chip technology for advancement of drug development and toxicology. Adv. Healthc. Mater. 4, 1426-1450. doi: 10.1002/adhm.201500040

Dong, R., Zhao, X., Guo, B., and Ma, P. X. (2016). Self-healing conductive injectable hydrogels with antibacterial activity as cell delivery carrier for cardiac cell therapy. ACS Appl. Mater. Interfaces 8, 17138-17150. doi: 10.1021/acsami.6b04911

Escalona, M. H., Briones, J. R., and Pawlicka, A. (2012). Sodium alginatebased ionic conducting membranes. Mol. Cryst. Liquid Cryst. 554, 221-231. doi: $10.1080 / 15421406.2012 .634329$

Feng, L., and Liu, Z. (2011). Graphene in biomedicine: opportunities and challenges. Nanomedicine 6, 317-324. doi: 10.2217/nnm.10.158

Ghanem, A. F., and Abdel Rehim, M. H. (2018). Assisted tip sonication approach for graphene synthesis in aqueous dispersion. Biomedicines. 6:63. doi: 10.3390/biomedicines6020063

Gianak, O., Pavlidou, E., Sarafidis, C., Karageorgiou, V., and Deliyanni, E. (2018). Silk fibroin nanoparticles for drug delivery: effect of bovine serum albumin and magnetic nanoparticles addition on drug encapsulation and release. Separations 5:25. doi: 10.3390/separations5020025

Gonzalez-Mayorga, A., Lopez-Dolado, E., Gutierrez, M. C., Collazos-Castro, J. E., Ferrer, M. L., del Monte, F., et al. (2017). Favorable biological responses of neural cells and tissue interacting with graphene oxide microfibers. Biomater. Sci. 2, 8253-8263. doi: 10.1021/acsomega.7b01354

Guo, J., Niaraki-Asli, A. E., Williams, K. R., Lai, P. L., Wang, X., Montazami, R., et al. (2019). Viability of neural cells on 3D printed graphene bioelectronics. Biosensors 9:112. doi: 10.3390/bios9040112

Hashemi, N., Lackore, J. M., Sharifi, F., Goodrich, P. J., Winchell, M. L., and Hashemi, N. (2016). A paper-based microbial fuel cell operating under continuous flow condition. Technology 4, 98-103. doi: $10.1142 / S 2339547816400124$

Heo, D. N., Lee, S.-J., Timsina, R., Qiu, X., Castro, N., and Zhang, L. G. (2019). Development of 3D printable conductive hydrogel with crystallized PEDOT:PSS for neural tissue engineering. Mater. Sci. Eng. C 99, 582-590. doi: 10.1016/j.msec.2019.02.008

Ho, S. S., Keown, A. T., Addison, B., and Leach, J. K. (2017). Cell migration and bone formation from mesenchymal stem cell spheroids in alginate hydrogels are regulated by adhesive ligand density. Biomacromolecules 18, 4331-4340. doi: 10.1021/acs.biomac.7b01366

Inal, S., Hama, A., Ferro, M., Pitsalidis, C., Oziat, J., Iandolo, D., et al. (2017). Conducting polymer scaffolds for hosting and monitoring 3D cell culture. $A d v$. Biosyst. 1:1700052. doi: 10.1002/adbi.201700052

Ismail, Z., Abdullah, A. H., SAbidin, A. S. Z., and Yuosoh, K. (2017). Production of functional graphene by kitchen mixer: mechanism and metric development for in situ measurement of sheet size. J. Nanostruct. Chem. 7, 231-242. doi: 10.1007/s40097-017-0233-6

Kang, E., Choi, Y. Y., Chae, S.-K., Moon, J.-H., Chang, J.-Y., and Lee, S.-H. (2012). Microfluidic spinning of flat alginate fibers with grooves for cell-aligning scaffolds. Adv. Mater. 24, 4271-4277. doi: 10.1002/adma.201201232

Kim, B., Kim, I., Choi, W., Kim, S. W., and Lim, G. (2007). Fabrication of cellencapsulated alginate microfiber scaffold using microfluidic channel. J. Manuf. Sci. Eng. 130:021016. doi: 10.1115/1.2898576

Leong, M. F., Lu, H. F., Lim, T. C., Narayanan, K., Gao, S., Wang, L. Y., et al. (2016). Alginate microfiber system for expansion and direct differentiation of human embryonic stem cells. Tissue Eng. Part C Methods 22, 884-894. doi: $10.1089 /$ ten.tec.2015.0561

Liu, X., Miller II, A. L., Park, S., Waletzki, B. E., Terzic, A., Yaszemskiab, M. J., et al. (2016). Covalent crosslinking of graphene oxide and carbon nanotube into hydrogels enhances nerve cell responses. J. Mater. Chem. B 4:6930. doi: 10.1039/C6TB01722C

Liu, X., Miller II, A. L., Park, S., Waletzki, B. E., Zhou, Z., Terzic, A., et al. (2017). Functionalized carbon nanotube and graphene oxide embedded electrically conductive hydrogel synergistically stimulates nerve cell differentiation. Appl. Mater. Interfaces 9, 14677-14690. doi: 10.1021/acsami.7b02072

Lu, M. (2016). Aligning carbon nanofibers in PCL microfibers using microfluidic method: An approach to efficiently improve electrical conductivity and mechanical strength (Master's thesis), Iowa State University, Ames, IA, United States.

Mawad, D., Artzy-Schnirman, A., Tonkin, J., Ramos, J., Inal, S., Mahat, M. M., et al. (2016). Electroconductive hydrogel based on functional poly(ethylenedioxy thiophene). Chem. Mater. 28, 6080-6088. doi: 10.1021/acs.chemmater.6b01298

McNamara, M. C., Pretzer, R. J., Montazami, R., and Hashemi, N. N. (2019a). Shear at fluid-fluid interfaces affects the surface topologies of alginate microfibers. Clean Technol. 1, 265-272. doi: 10.3390/cleantechnol1010018

McNamara, M. C., Sharifi, F., Okuzono, J., Montazami, R., and Hashemi, N. N. (2019b). Microfluidic manufacturing of alginate fibers with encapsulated astrocyte cells. ACS Appl. Bio Mater. 2, 1603-1613. doi: $10.1021 /$ acsabm.9b00022

McNamara, M. C., Sharifi, F., Wrede, A. H., Kimlinger, D. F., Thomas, D.G., Vander Wiel, J. B., et al. (2017). Microfibers as physiologically relevant platforms for creation of 3D cell cultures. Macromol. Biosci. 17:1700279. doi: $10.1002 /$ mabi.201700279

Meng, Z.-J., Wang, W., Xie, R., Ju, X.-J., Liu, Z., and Chu, L.-Y. (2016). Microfluidic generation of hollow Ca-alginate microfibers. Lab Chip 16:2673. doi: 10.1039/C6LC00640J

Mohanty, S., Amato, L., Heiskanen, A., Keller, S. S., Boisen, A., Dufva, M., et al. (2013). "Conducting pyrolised carbon scaffold for tissue engineering," in 29th International Conference on Micro- and Nano-Engineering (London).

Niaraki-Asli, A. E., Guo, J., Lai, P. L., Montazami, R., and Hashemi, N. N. (2019) High-yield production of aqueous graphene for electrohydrodynamic dropon-demand printing of biocompatible conductive patterns. Biosensors 10:1. doi: 10.3390/bios10010006

Niemczyk, B., Sajkiewicsz, P., and Kolbuk, D. (2018). Injectable hydrogels as novel materials for central nervous system regeneration. J. Neural Eng. 15:051002. doi: 10.1088/1741-2552/aacbab

Onoe, H., and Takeuchi, S. (2015). Cell-laden microfibers for bottom-up tissue engineering. Drug Discov. Today 20, 236-246. doi: 10.1016/j.drudis.2014.10.018

Osipova, E. D., Komleva, Y. K., Morgun, A. V., Lopatina, O. L., Panina, Y. A., Olovyannikova, R. Y., et al. (2018). Designing in vitro blood-brain barrier models reproducing alterations in brain aging. Front. Aging Neurosci. 10:234. doi: 10.3389/fnagi.2018.00234

Pattammattel, A., and Kumar, C. V. (2015). Kitchen chemistry 101: multigram production of high quality biographene in a blender with edible proteins. $A d v$. Funct. Mater. 25, 7088-7098. doi: 10.1002/adfm.201503247

Pemathilaka, R. L., Caplin, J. D., Aykar, S. S., Montazami, R., and Hashemi, N. N. (2019). Placenta-on-a-chip: in vitro study of caffeine transport across placental barrier using liquid chromatography mass spectrometry. Glob. Challenges 3:180112. doi: $10.1002 /$ gch 2.201800112

Reina, G., Gonzalez-Dominguez, J. M., Criado, A., Vazquez, E., Bianco, A., and Prato, M. (2017). Promises, facts and challenges for graphene in biomedical applications. Chem. Soc. Rev. 46, 4400-4416 doi: 10.1039/C7CS00363C 
Santos, V. H. D., Pfeifer, J. P. H., Souza, J. B. D., Stievani, F. D. C., Hussni, C. A., Golim, M. D. A., et al. (2019). Evaluation of alginate hydrogel encapsulated mesenchymal stem cell migration in horses. Res. Vet. Sci. 124, 38-45. doi: 10.1016/j.rvsc.2019.02.005

Sechi, D., Greer, B., Johnson, J., and Hashemi, N. N. (2013). Three-dimensional paper-based microfluidic device for assays of protein and glucose in urine. Anal. Chem. 85, 10733-10737. doi: 10.1021/ac4014868

Serrano, M. C., Feito, M. J., Gonzalez-Mayorga, A., Diez-Orejas, R., Matesanz, M. C., and Portoles, M. T. (2018). Response of macrophages and neural cells in contact with reduced graphene oxide microfibers. Biomater. Sci. 6, 2987-2997. doi: 10.1039/C8BM00902C

Sharifi, F., Bai, Z., Montazami, R., and Hashemi, N. (2016a). Mechanical and physical properties of poly(vinyl alcohol) microfibers fabricated by a microfluidic approach. RSC Adv. 6, 55343-55353. doi: 10.1039/C6RA09519D

Sharifi, F., Kurteshi, D., and Hashemi, N. (2016b). Designing highly structured polycaprolactone fibers using microfluidics. J. Mech. Behav. Biomed. Mater. 61, 530-540. doi: 10.1016/j.jmbbm.2016.04.005

Sharifi, F., Patel, B. B., Dzuilko, A. K., Montazami, R., Sakaguchi, D. S., and Hashemi, N. (2016c). Polycaprolactone microfibrous scaffolds to navigate neural stem cells. Biomacromolecules 17, 3287-3297. doi: 10.1021/acs.biomac.6b01028

Sharifi, F., Patel, B. B., McNamara, M. C., Meis, P. J., Roghair, M. N., Lu, M., et al. (2019). Photo-cross-linked poly(ethylene glycol) diacrylate hydrogels: spherical microparticles to bow tie-shaped microfibers. ACS Appl. Mater. Interfaces 11, 18797-18807. doi: 10.1021/acsami.9b05555

Shin, S.-J., Park, J.-Y., Lee, J.-Y., Park, H., Park, Y.-D., Lee, K.-B., et al. (2007). “On the fly" continuous generation of alginate fibers using a microfluidic device. Langmuir 23, 9104-9108. doi: 10.1021/la700818q

Sirivisoot, S., Pareta, R., and Harrison, B. S. (2014). Protocol and cell responses in three-dimensional conductive collagen gel scaffolds with conductive polymer nanofibres for tissue regeneration. Interface Focus 4:20130050. doi: 10.1098/rsfs.2013.0050

Thayumanavan, N., Tambe, P., Joshi, G. M., and Shukla, M. (2014). Effect of sodium alginate modification of graphene (by 'anion- $\pi$ ' type of interaction) on the mechanical and thermal properties of polyvinyl alcohol (PVA) nanocomposites. Composite Interfaces 21, 487-506. doi: $10.1080 / 15685543.2014 .879512$

Wang, S., Guan, S., Xu, J., Li, W., Ge, D., Sun, C., et al. (2017). Neural stem cell proliferation and differentiation in the conductive PEDOTHA/Cs/Gel scaffold for neural tissue engineering. Biomater. Sci. 5, 2024-2034. doi: 10.1039/C7BM00633K

Wang, W., Tan, B., Chen, J., Bao, R., Zhang, X., Liang, S., et al. (2018). An injectable conductive hydrogel encapsulating plasmid DNA-eNOs and ADSCs for treating myocardial infarction. Biomaterials 160, 69-81. doi: 10.1016/j.biomaterials.2018.01.021

Wei, D., Sun, J., Bolderson, J., Zhong, M., Dalby, M. J., Cusack, M., et al. (2017). Continuous fabrication and assembly of spatial cell-laden fibers for a tissuelike construct via a photolithographic-based microfluidic chip. Appl. Mater. Interfaces 9, 14606-14617. doi: 10.1021/acsami.7b00078

$\mathrm{Wu}, \mathrm{D}$., and Zhong, W. (2019). A new strategy for anchoring a functionalized graphene hydrogel in a carbon cloth network to support a lignosulfonate/polyaniline hydrogel as an integrated electrode for flexible high areal-capacitance supercapacitors. J. Mater. Chem. A 7, 5819-5830. doi: 10.1039/C8TA11153G

Zhang, Q., Beirne, S., Shu, K., Esrafilzadeh, D., Huang, X.-F., and Wallace, G. G. (2018). Electrical stimulation with a conductive polymer promotes neurite outgrowth and synaptogenesis in primary cortical neurons in 3D. Sci. Rep. 8:9855. doi: 10.1038/s41598-018-27784-5

Conflict of Interest: The authors declare that the research was conducted in the absence of any commercial or financial relationships that could be construed as a potential conflict of interest.

Copyright (c) 2020 McNamara, Niaraki-Asli, Guo, Okuzono, Montazami and Hashemi. This is an open-access article distributed under the terms of the Creative Commons Attribution License (CC BY). The use, distribution or reproduction in other forums is permitted, provided the original author(s) and the copyright owner(s) are credited and that the original publication in this journal is cited, in accordance with accepted academic practice. No use, distribution or reproduction is permitted which does not comply with these terms. 